\title{
Os guias turísticos em Berlim
}

Irlys Alencar Firmo Barreira

Assim como os antropólogos, seguindo Lévi-Strauss, afirmam a evidência de temas bons para se pensar, é possível também acrescentar a essa assertiva a existência de lugares bons para se pensar. Bons, por suscitarem a emergência de problemáticas transcendentes ao próprio contexto de enunciação, integrando-se ao acervo dos notórios assuntos universais. Refirome aqui a Berlim, cidade onde questões alusivas à memória e suas expressões discursivas e estéticas parecem relevantes sob diversos aspectos. 0 passado da cidade e do país como símbolo da história mundial; a divisão espacial no contexto da G uerra Fria; a unificação figurada na "queda do muro" que se tornou emblema contemporâneo da democracia e da derrocada do socialismo. Em síntese, a cidade de Berlim é celeiro de um conjunto vasto de memórias que parecem inesgotáveis e em permanente evocação.

As imagens topográficas, acompanhadas de descrições e roteiros difundidos hojeem postais, catálogos eguias turísticos, são expressões denarrativas da cidade. Apresentam formas dispersas e fragmentadas de pequenos relatos adequados à fluidez eà descontinuidade da vida urbana, constituindo uma importante via de pesquisa das representações e das memórias projetadas no espaço. É sobre essematerial informativo quese detém a perspectiva de reflexão do presente texto, voltado à análise do modo como diferentes espaços, monumentos e edificações são evocados e submetidos a pro- 
1.0 material que serviu de referência às reflexões deste texto foi obtido durante minha estadia em Berlim, entre 15 deagosto e 15 de novembro de $2001.0 \mathrm{~s}$ dados coletadosnoscatálogos, folhetoseguias turísticosforam obtidos em museus, livrarias e bibliotecas. As edições mais antigas e os catálogos produzidos na Alemanha 0 riental foram obtidos na Stadt Bibliothek de Berlim. As citações dos catálogos contidasno presente artigo foram traduzidas pela autora. Gostaria de registrar meus agradecimentos especiaisà professora Renate Rott, pelo convite para estágio na FreieU niversität Berlin no programa Capes/D AAD. cessos simbólicos revelados na disputa entre memórias e constantes definições da relação entre passado e presente ${ }^{1}$.

O s guias turísticos não se separam das imagens construídas e reconstruídas da cidade, em diferentes circunstâncias de sua história. N essa perspectiva, as idéias aqui expostas priorizam, sobretudo, as referências aos momentos de destruição da cidade durante a Segunda Guerra M undial, à divisão posterior do espaço berlinense e à construção da "N ova Berlim".

As narrativas, na condição de metáforas tomadas por empréstimo do mundo literário, expressam discursos instituídos sobre a cidade, originados de diferentes fontes. D iscursos que são não apenas fruto de práticas e intervenções de diferentes atores sociais, mas expressão de formas legitimadas de apresentar a cidade. 0 passado e sua manifestação como patrimônio cultural não se separam de uma política da memória, considerando-se a eleição feita do que permanece, do que se preserva e do que se expõe como reminiscência temporal (cf. Choay, 1999).

U ma rápida exposi ção sobre os guias e os catálogos da ci dade de Berlim torna-se relevante no desenvolvimento das idéias aqui apresentadas.

Guias turísticos: um espaço peculiar de construção de narrativas

São várias as formas de apresentar Berlim aos que desejam conhecêla em curto espaço de tempo. 0 material informativo a que tive acesso, destinado a essa finalidade, compõe-se de catálogos e guias editados de manei ra bastante diversificada. D estacam-se volumes com encadernação em forma de livro, contendo textos e ilustrações; folhetos de rápido manuseio, referentes à cidade inteira ou a uma área específica, produzidos em edições especializadas, sobre pontos considerados dignos de atração para o visitante. A difusão desse material em livrarias, pontos turísticos e museus evidencia sua destinação a um público específico: os turistas. Também nas bibliotecas, a exemplo da Stadt Bibliothek de Berlim, é possível encontrar edições de folhetos, livros e catálogos de várias épocas, classificados no índice catalográfico como história ou cidade e imagem, comprovando a interface dessa produção com as ciências sociais, incluindo arquitetura e urbanismo.

A autoria desses informativos nem sempre é evidente, embora seja possível encontrar, sobretudo em catálogos e guias especializados, o registro de fotógrafos e escritores de renome. As versões são feitas em várias línguas, estando presente também, em um mesmo veículo, o texto original em alemão e as respectivas traduções em inglês, francês e espanhol. 
O s guias e os catálogos têm em comum o público a que se dirigem geral mente o visitante alemão ou estrangeiro - , constituindo-senum veículo que objetiva "apresentar a cidade" pela recomendação da visita a determinados locais eque, como o próprio nome diz, écontrário à atitude daqueles que caminham a esmo pela cidade, retendo na memória apenas sua forma subjetiva e peculiar de apreendêla. A racionalidade no uso do tempo recomendada ao visitante difere da concepção ideal de conhecimento do espaço urbano de Walter Benjamin, para quem: "Importa pouco não saber orientar-se em uma cidade. Perder-se, ao contrário, em uma cidade, como quem se perde em um bosque, requer aprendizagem" (Benjamin, 1962, p. 15).

O s materiais informativos funcionam, nesse sentido, como uma direção que evita "caminhos incertos" ou desvios de um modo planejado de conhecer a cidade. $E$, se em al guns momentos as páginas de um guia destacam um aconsel hamento sobre uma possível travessia dispersa de certas ruas, é para logo mais apresentar uma direção ou lugar onde é "impossível não se deter", sob pena de não haver "conhecido" de fato a cidade. É sobretudo após haver efetivado o roteiro previamente estabelecido que 0 observador pode construir seu próprio percurso, pois "durante a primeira visita é aconselhável obter uma impressão global recorrendo às proximidades das avenidas U nter den Linden e Kurfrüstendamm. D epois pode simplesmente deixar-se levar pela magia da cidade" (Armin, 2000, p. 5).

A maioria dos guias é composta de fotos e imagens que têm papel preponderante na informação, funcionando como mostra antecipada do monumento ou local a ser visitado. As tomadas das fotos, aéreas ou em close, diurnas ou noturnas, são dotadas de luminosidade e amplitude bastante semelhantes àquel as que se vêem nos cartões-postais. 0 s registros fotográficos, feitos das cúpulas das edificações ou de seus interiores, val orizam os espaços remodelados, evidentes, sobretudo, nos dez últimos anos, como parte do processo de construção da "N ova Berlim". São fotos que, ao privilegiarem os monumentos e seus interiores, excluindo geral mente a presença de pessoas, funcionam como quadros pai sagísticos capazes de permitir o conhecimento da cidade em diferentes dimensões topográficaš: do alto da torre Alexanderplatz, do balão na Potsdamer Platz, dos subterrâneos dos transportes urbanos ou mesmo através das escavações da "topografia do terror", onde o passado trágico implanta a memória dolorosa da guerra.

Compostos de introdução, fotos e apresentação de locais a serem vistos, os materiais topográficos sobre o espaço urbano são como vitrine que
2. Algunsguias apresentam a cidade em vistas aéreas, enfatizando sobretudo as cúpulas de igrejas e, mais recentemente, a reforma da cúpula do Reichstag. 
3. Ver, a esse respeito, 0 livro deFontane(1968), reeditado em uma série especial voltada para 0 registro de lugarescaracterísticos, artísticosehistóricos. Segundo notado editor: "Estas séries começam ondeosguiascomuns terminam. Apre sentam lugares que se distinguem pelabelezade eventos, paisagem, artes ehistória, retratadosnos estudos de escritores famosos. 0 texto encoraja visitantes, não apressados e residentes interessados, a enriquecer seusconhecimentospor meio do poder de descrição dos artistas". pretende conter uma espécie de "identidade citadina”: a visão panorâmica do que constitui foco de atração e diferenciação das demais cidades. Em certo sentido, reafirmam a instituição de "lugares", na acepção discutida por Augé (1998), capazes de registrar experiências passadas que almejam se contrapor ao provisório ou efêmero que marca a paisagem atual das grandes metrópoles.

As produções catalográficas expressam também o fenômeno da editoração, típico dos meios de comunicação de massa, com exemplares em diferentes línguas. A existência de fotos padronizadas que ilustram parte significativa dos guias e dos catálogos supõe, portanto, a vigência de uma "indústria de consumo", exemplificada nas várias edições sobre o muro de Berlim, sobre a Potsdamer Platz, o M itte e determinados locais eleitos como pontos emblemáticos da cidade.

A edição de catálogos e livros, narrando por meio de gravuras e fotos a "história da cidade de Berlim", faz parte de uma tradição literária. Além de catálogos dos anos de 1930, ilustrados com gravuras e textos que mostram praças, palácios e edificações, escritores famosos como Theodor Fontane produziram importantes registros, posteriormente editados em uma série especial de guias sobre a cidade 3 . As narrativas são caracterizadas, nesse contexto, pela descrição de zonas paisagísticas ilustradas com gravuras típicas dos meados do século XIX, nas quais se percebe a imagem de uma visão integrada entre homem e natureza.

Em certo sentido, os guias turísticos das últimas décadas são uma herança readaptada desses catálogos e narrativas sobre a cidade, levando-se em consideração a linguagem e a imagem padronizadas desses materiais. O s guias recentes apresentam, no entanto, informações resumidas, acompanhadas de fotos primorosas que substituem antigas gravuras, destacando-se certos locais que motivam a existência de um passeio com roteiro. $A$ natureza prática dos guias atuais está na síntese das descrições e na explicitação dos acessos, incluindo ruas e meios de transporte.

O s mapas e guias são também legitimadores de cenários e emblemas da memória social, pois, assim como se diz que é impossível ir a Paris sem contemplar a torre Eiffel (cf. Loyrette, 1992, pp. 475-501), também não é possível "conhecer" outras cidades sem o acesso a determinados acervos que são produtos de investimentos materiais e simbólicos, em torno de sua conservação e difusão.

O s guias impressos são também sintoma dos processos sociais de anonimato que ocorrem na metrópole contemporânea, em substituição à infor- 
mação pessoal, advinda do contato interativo face a face. Lembro, aqui, a reflexão de Simmel (1976), quando se refere à reserva, à desconfiança e ao estranhamento dos habitantes da cidade grande, compensados, no entanto, pela construção de outras formas elementares de inserção urbana. 0 pensamento do autor, voltado à explicação de especificidades da sociabilidade citadina, pode também dar subsídios para se pensar sobre a função dos guias como objeto contemporâneo de socialização de turistas numa grande cidade.

O s mapas e os guias poderiam ser vistos, nesse sentido, como substitutos do narrador, isto é, aquele que adquire o conhecimento sobre a cidade associado à memória eà experiência de algo vivido em al gum lugar (cf. Benjamin, 1962). Se os materiais informativos que compõem a "história da cidade" são relatados por um autor, este, na maioria das vezes, é desconhecido edirigesuas informações eapelos para um conjunto potencial de pessoas pertencentes a um espaço público impessoal, tendo em vista o fato de que "hoje em dia é ao turista, mais que ao flâneur, que a nova cultura da cidade quer apelar, ao mesmo tempo em quetemeo indesejável duplo do turista: 0 migrante expatriado" (H uyssen, 2000, p. 91).

0 sroteiros contidos nos materiais informativos aparecem como evidentes e reveladores da "história da cidade", organizando determinados pontos fixos dotados de múltiplas temporalidades, a exemplo da indicação de visita a um monumento imperial, seguida de uma descrição do "muro deBerlim" ou do museu egípcio. É essa marca descontínua de símbolos superpostos quepode despertar o plano da curiosidade: a organização de peças históricas que seguem a lógica do colecionador. Em certo sentido, o turista habitual é, ele próprio, um colecionador de curiosidades materializadas nas visitas, nas fotos e nas compras pelas quais vai montando o seu acervo de conhecimentos, baseado em itinerários cuja peculiaridade é estarem em movimento 4. N ão por acaso, Bauman (1998) aponta o turista como expressão típica da pós-modernidade, considerando a montagem de suas experiências vividas deforma desconexa no tempo eno espaço.

O s guias e os catálogos, vistos indistintamente e de forma rápida, podem ser considerados vé́culos de consumo que dão sentido à experiência e ao conhecimento da cidade. É importante, no entanto, identificar diferenças marcantes entre materiais informativos, a exemplo daqueles produzidos por ocasião da divisão política de Berlim. O s guias refletem, em tal perspectiva, os conflitos simbólicos entre as narrativas da cidade, confirmando o princípio segundo o qual aquilo
4. U ma discussão sobre o turista como figura típicada pós-modernidadeencontra-se em Bauman (1998). 
[...] que cada grupo hegemônico estabelece como patrimônio nacional e relato legítimo de cada época é o resultado de operações de seleção, combinação e encenação que mudam segundo os objetivos das forças que disputam a hegemonia e a renovação de seus pactos (C anclini, 1997, p. 126).

A discussão a seguir apresenta de forma paradigmática a situação de disputa entre as formas de apresentar Berlim, confirmando o caráter diversificado das narrativas.

As narrativas da cidade como disputa simbólica

U m segmento de guias e catálogos sobre Berlim demonstra a existência de discursos que competem quanto às versões da cidade a serem difundidas ao público dentro e fora da Alemanha. Esses materiais apontam a querela instituída no contexto da Guerra Fria e da divisão do país, ostentada no registro peculiar de espaços e intervenções urbanas.

U m dos catálogos editados na D eutsche $D$ emokratische Republik (República D emocrática Alemã, RD A), por ocasião do 750 aiversário de Berlim, contendo versões em russo, inglês, francês e alemão, traz elementos importantes para se pensar sobre essa questão (cf. Brückner, 1987, pp. 1017). As primeiras imagens dessa edição mostram pessoas andando etomando sorvete, crianças, homens e mulheres. Segue-se, nas demais páginas, uma visão panorâmica do centro da cidade, incluindo outras imagens que representam uma espécie de símbolo de potência da Alemanha 0 riental: a torre detelevisão eaC âmara do Povo, ap resentada em funcionamento, com participação depessoas votando em um plenário. 0 catálogo, apósa exposição deal gumas fotos, explana a "história da cidade" nos seguintes termos:

[...] 750 anos de existência mudam uma cidade ligada à história da Alemanha e sob muitos pontos de vistaà história européia emundial. Vila próspera, centro político, econômico, intelectual ecultural do primeiro Estado socialista sob o sol da Alemanha, capital da República D emocráticaAlemã, ondea paz éo princípio supremo da política, Berlim festeja seu 750 aniversário [...]. A capital da RD A está profundamente enraizada nas tradições ricas e múltiplas dos 750 anos de história da cidade. N esta cidadeépreservado o fruto do trabalho edas lutas dasclassestrabal hadorasno curso dos sécul os. As aspirações das forças e das personalidades progressistas, democráticas ehumanitárias, as obras culturaisartísticas e científicas, qualquer quetenha sido o meio social de onde emergiram (Brückner, 1987, pp. 15-17). 
A linguagem heróica e ufanista do catálogo é percebida, sobretudo, nos relatos do final da guerra, em que "os inválidos, doentes e velhos foram obrigados a lutar até 0 final obedecendo a última ordem, até que a chegada da armada vermelha deu sua grande contribuição à derrubada do fascismo". A ilustração caricaturada desse momento é a célebre foto do soldado soviético, sob os escombros, levantando a bandeira da U nião Soviética, ostentada como símbolo de libertação do nazismo. 0 utras fotos do catálogo incluem rituais do Primeiro de $\mathrm{M}$ aio, representantes oficiais do governo e multidões nas ruas, compondo exposições de uma imagem da cidade reconciliada com seus ideais: "Tal como uma fênix renascendo das cinzas de uma terrível catástrofe, Berlim na festa do seu 750 aniversário respira saúde onde a vida é ritmada pelo esforço dos berlinenses e de toda população do país" (Idem, p. 16).

A apresentação de Berlim, como se pode perceber, encontra-se fortemente vinculada à afirmação do socialismo como ideologia capaz, em um primeiro momento, de libertar a cidade e, depois, preservá-la dos chamados ataques inimigos.

O utras ilustrações mostram ainda monumentos, esculturas e fatos re presentativos do socialismo, buscando expressar uma narrativa citadina na qual política, trabalho e vida cotidiana estão plenamente reconciliados em ideais também extensivos ao domínio da arte: "A eclosão de uma cultura socialista na RD A se traduz na emergência de novos gêneros dramáticos". A exposição fotográfica de áreas de lazer, como piscinas, parques e florestas, conclui a unidade do conjunto harmonioso difundido para o restante do mundo como documento importante de afirmação de tranqüilidade, em reação à imagem negativa da repressão do regime socialista transmitida por ocasião do debate ideológico travado durante a Guerra Fria.

No plano dos espaços urbanos considerados mais representativos, 0 catálogo destaca a Alexanderplatz, um dos pontos de orgulho da RDA:

A praça está intimamente ligada à história de Berlim. Ela deve seu nome a uma visita efetuada pelo tzar Alexandrel da Rússia e foi centro de numerosos combates envolvendo trabalhadores revolucionários [...] ao percorrer o olhar sobre a nossa capital socialista, o visitante só pode admirar o centro moderno da cidade, traduzindo o esforço generoso de construção e uma concepção urbana equilibrada.

0 modo peculiar de apresentar a cidade, por meio dos materiais contidos nos catálogos produzidos na Berlim O riental, pode ser percebido des- 
de a exposição das fotos até a linguagem que reivindica legitimidade de representação da cidade em seu conjunto urbano.

Considerando, por exemplo, que a separação da Alemanha foi acompanhada pela fundação do "Estado separatista de Bonn", outro catálogo de nominado Berlin Hauptsadt der DDR, de Werner Fahr (1965), afirma o processo de reforma urbana da cidade:

A construção da cidade avançou rapidamente. 0 centro recebe um aspecto novo: os prédios destinados aos órgãos políticos e administrativos de nosso Estado são construídos na praça M arx-Engels. É aqui que se elevaráa torre de televisão de 360 metros. A capital daRD A conta com mais de 1 milhão dehabitantes. São hóspedes cordiais para bons amigos. N ossa capital Ihe agradará. Visitenos.

O s catálogos editados na Alemanha 0 riental, por ocasião do 750ำ aniversário da cidade, apresentam a construção de dois momentos históricos enunciados tanto por meio das fotos como da linguagem que sinaliza a existência de um "antes" e de um "depois". Ao tempo histórico de fundação do equipamento urbano associam-se os momentos de sua destruição e de sua reconstrução, sendo esta apresentada como luta contra o fascismo eimagem do progresso. As referências ao muro são omitidas, destacando-se uma idéia sutil de unidade que é passada ao longo de todo o texto do catálogo.

O s guias e os catálogos editados na Berlim 0 cidental, por outro lado, acentuam os espaços de reconstrução urbana, privilegiando, por contraste, os equi pamentos e os investimentos situados nessa zona da cidade. Alguns trechos da introdução do catálogo Berlim 1945/Berlim hoje (cf. Curlis, 1965, pp. 3-4) caracterizam com nitidez o fenômeno:

0 ano zero na nova história da Alemanha é também 0 ano zero para a antiga capital do Reich. D esde 1965 Berlim tornou-se o centro industrial mais importante do continente [...] em 1965 o turista descobre sob as margens do Spree uma metrópolemoderna que foi construída sobre os antigos bairros totalmente destruídos. A tristeza provocada pelo que foi irremediavelmente perdido é mitigada pelo orgulho elevado pelo espetáculo de realizações novas.

O s catálogos e os guias produzidos pela A lemanha O riental, ao contrário daqueles produzidos pela Alemanha 0 cidental, referem-se minimamente à divisão da cidade. A construção do muro é justificada pela "exis- 
tência de oitenta organizações de espionagem e de subversão que operavam a partir de Berlim 0 este para desestabilizar politicamente a RDA".

As narrativas da destruição e da reconstrução urbanas fazem parte de um conjunto significativo de catálogos que visam a apresentar a cidade a partir de um ponto de origem. $\mathrm{N}$ ão por acaso, muitos deles têm o nome "Stunde Null" (hora zero), identificando o momento em que a cidade é destruída e reconstruída. As edições produzidas em cada uma das Alemanhas traduzem essa dimensão de morte e renascimento, que recupera uma certa mitologia das origens típicas de cidades ou sistemas políticos (cf. G irardet, 1987). 0 ponto zero evoca também a idéia de um Salvador e de um momento histórico em que tudo parece recomeçar de modo positivo.

Se as situações de destruição e reconstrução caracterizam uma série de catálogos, produzidos tanto na Alemanha 0 riental como na 0 cidental, a apresentação dos processos de reconstrução difere na busca dos melhores porta-vozes da recuperação de uma cidade destruída. N essa disputa entre versões de uma história a ser explanada, destacam-se também as narrativas sobre o muro.

Registros catalográficos do muro

0 muro constitui um dos pontos emblemáticos bastante presente nos guias e nos roteiros, suscitando visitações permanentes. Vendas de "pedaços do muro" em cartões-postais e adornos em forma de relíquias refletem bem os significados atribuídos a esse ícone da história berlinense ${ }^{5}$, conhecido por designações como muro antifascista, segundo a terminologia da RDA, ou "muro da vergonha", segundo a acepção dos críticos e dos descontentes com a divisão da cidade como símbolo da Guerra Fria e espaço de afirmação do socialismo.

Inaugurado em 13 de agosto de 1961, o muro inspirou, a cada "aniversário" de sua existência, a realização de rituais de contestação e posteriores comemorações oficiais, que exemplificam as diferentes possibilidades de apropriação simbólica de uma edificação urbana (cf. Stein, 1997). A queda do muro foi, nesse sentido, mais do que a recomposição da unidade urbana, a expressão visível da perda da hegemonia socialista ou da abertura de mocrática no mundo.

O "M uro de Berlim" faz parte, hoje, do roteiro dos guias turísticos e catálogos de apresentação da cidade. Por exemplo, o guia Walk the wall possui mapa específico em várias línguas, contendo uma narrativa didática
5.0 s efeitos da divisão da cidade de Berlim sobre as identidades citadinas, bem como a instauração deuma assimetria entre as duas zonas espaciais, foram bastante discutidos na literatura antropológica ehistórica, destacando-se questões de ordem econômica esocial como ponto de demarcação das diferenças. Ver Bornerman (1997). 
dirigida aos visitantes e a apresentação do "caminho do muro", caracterizado como "o traço mais recente do passado de Berlim". É importante acompanhar a forma como "a história do muro" é contada aos visitantes, sendo um importante móvel simbólico de denúncia:

Turistas de todo o mundo não poderão imaginar sua monstruosa construção e influência. Para isso nós fizemos a rota do muro sobre o nosso mapa da cidade. Ele deve também servir como lembrança para todas as pessoas que moram em Berlim e mostrar até onde o fanatismo pode levar.

0 muro é apresentado desde a sua fundação, enfocando etapas que apontam o papel dos artistas na elaboração de desenhos sobre sua superfície e também filmes como o de W im Wenders, $\mathrm{H}$ immel über Berlim (Asas do desejo), que ostenta imagen s do local em várias tomadas decena. A narrativa presente em Walk the wall mostra várias declarações das vítimas que tentaram atravessar a zona de acesso, referindo-se também a lugares históricos estratégicos, que tiveram as suas funções alteradas depois do soerguimento da barreira, como foi o caso da Potsdamer Platz. U m dos pontos de destaque nas narrativas éa Bernauer Strasse, rua queficou dividida ao meio pelo muro e que abrigava também uma igreja (capela da reconciliação), demolida por localizar-se na frontei ra entre leste e oeste, e posteriormente reconstruída. A rua, percebida como símbolo da divisão, transformou-se também em ícone da "confrontação entre dois sistemas mundiais", segundo o texto explicativo do guia.

A crítica à existência do muro acompanha o registro de sua queda, vista como exaltação e recomposição da unidade perdida. N esses termos, é importante recorrer a outro veículo informativo, El Muro de Berlín, onde encontramos as palavras de Eberhard D iepgen, prefeito de Berlim:

Q uem percorre hoje as ruas de Berlim não pode imaginar como uma barreira de lambris e pua manteve separada e dividida por quase trinta anos esta metrópole pal pitante, cheia de vida, aberta ao mundo. [...] 0 s restos do muro são recordação e exortação. Recordam a segunda ditadura do século XX em território alemão e ante todas as vítimas. Exortam a uma decidida entrada em ação pela paz, a liberdade e a justiça. Agora Berlim é a capital da Alemanha livre e reunificada, que tem encontrado seu lugar reconhecido na comunidade internacional, em paz com seus vizinhos e vinculada aos pactos ocidentais $(2001$, p. 3). 
0 museu Check Point Charlie constitui-se num dos locais onde se encontram os registros mais importantes da história do muro. Antes de ser museu, a principal função do Check Point era guardar a área de acesso na fronteira entre as zonas leste e oeste da cidade. U ma enorme placa indicativa, até hoje preservada e posta na entrada do atual museu, informa: "Você está deixando o setor americano". 0 museu, situado próximo à antigafronteira, passou a sediar, inicialmente, um grupo de estudos e exibições sobreo muro e a cidade de Berlim durante o pós-guerra. Algumas exposições, como "O muro, de 13 deagosto atéhoje"; "Berlim - a cidade como porta e ponte para a Europa"; "Pintores interpretam o muro"; "D e G handi a Walesa - combate pelos direitos humanos sem violência"; "Topografia da Alemanha- a Alemanha defronteira", hojeestão incorporadas ao acervo do museu, integrando-se às demais figurações que buscam representar a "história" do muro.

0 museu contém, além de diferentes sal as de exposições, fotos e relatos da interdição, acompanhados de objetos que teriam sido usados em tentativas de fuga por habitantes de Berlim $O$ riental. $M$ antendo uma concepção clara de crítica ao socialismo, o acervo não contém registros de moradores de Berlim 0 riental, que são apresentados apenas em sua insatisfação permanente revelada na tentativa freqüente de fuga.

0 muro reflete, espacialmente, diferentes momentos da história da cidade na descrição desses guias e mapas, sendo ponto de referência importante das narrativas construídas, que sinalizam marcas temporais referentes a um "antes" e um "depois". Por um período longo, simbolizou o rechaço da democracia e a intolerância às diferenças, o que tornou sua derrubada um momento especial de ruptura, como pode ser visto nas palavras poéticas de $D$ arnton sobre o dia oficial da abertura da fronteira:

Foi um momento mágico de tomada de posse de uma cidade por um povo. $\mathrm{Na}$ quinta, 9 de novembro, sob uma lua entre a sombra do Reichstag e a massa ameaçadora da Porta de Brandemburgo, o povo de Berlim dança sobre o muro, transformando a paisagem urbana mais cruel em uma cena de hilaridade e esperança, e colocando fim a um século de guerra (D arnton, 1991, p. 86).

A percepção da queda do muro como instauração de uma nova era encontra-se presente em vários guias e catálogos que mostram uma "N ova Berlim" unificada, com projeções para um futuro. 
A construção da Nova Berlim nos guias contemporâneos

A transformação de Berlim em nova capital da Alemanha unida foi acompanhada de amplas intervenções de reforma urbana, com o objetivo de recuperar prédios danificados e instituir outro visual de "cidade integrada". N aquele momento, a cidade era também palco de conflitos étnicos e de minorias, dando, ainda, visibilidade a antigas e novas desigualdades sociais (cf. Jaquand, 1994).

U ma espécie de reapropriação do antigo centro, que fazia parte de Berlim Leste, passa a ocorrer com intensidade, acompanhada também da ampliação de linhas de trem e outros serviços. O s catálogos e os guias editados após a queda do muro caracterizam-se por expressar, nitidamente, os investimentos urbanos na reconstrução da cidade, sob a ótica da unidade. A emergência de uma "nova Berlim" pode ser percebida na apresentação do Guia fotográfico a cores da capital Berlim:

Eis a nova Berlim - Berlim no limiar entre o segundo e o terceiro milênio. Agora que todos os foguetes do milênio já foram lançados, que todas as rolhas das garrafas de champanhe foram recicladas e que todos os hinos foram cantados, resta-nos uma Berlim dos superlativos: maior, mais cara, mais alta, mais luminosa, mais alegre, mais pomposa, mais rica, maisfascinante, mais poderosa, mais inteligentee mais imoral que todas as outras cidades vizinhas $(2000$, p. 1).

Essa dimensão superlativa da cidade, presente na mai oria dos catálogos e dos guias editados após a queda do muro, integra as concepções de renascimento embutidas de modo evidente, por exemplo, na quantidade de construções e de restaurações, na implantação de novas linhas férreas, que tornam a cidade, aos olhos dos visitantes, o "maior canteiro de obras da Europa". D efato, as construções em pontos específicos da cidade refletem um processo de renovação urbana com diferentes sentidos: recuperar a parte leste, fazer jus a grandes investimentos de companhias multinacionais e criar equipamentos urbanos compatíveis com a transferência da capital de Bonn para Berlim. A construção da "N ova Berlim" enseja uma ressignificação de sua história, contada sob a perspectiva do presente.

Ainda segundo a narrativa do mesmo guia:

Q uatro datas dominam a história mais recente da capital alemã: 1871, quando Berlim foi nomeada a capital do Império Alemão; 1945, quando a capital do Reich 
nazista foi tomada pelas tropas do Exército Vermelho; 1961, quando o hediondo M uro de Berlim foi construído numaúnica noite de agosto; e 1989, quando finalmente caiu o M uro que separou Berlim O riental de Berlim 0 cidental [...]. A Berlim do ano 2000, esta metrópole moderna com os seus milhões de habitantes, é uma conseqüência nova e historicamente lógica dos acontecimentos ocorridos em 1871, 1945, 1961 e 1989 (Idem, p. 2).

A designação dos locais e dos monumentos existentes na maior parte dos materiais catalográficos segue o rotei ro de uma descrição histórica, no qual se evidenciam a origem das edificações, os malefícios da guerra, a construção do muro e sua posterior destruição. Sobre a maneira de apresentar a "nova cidade" aos turistas, destaca-se também o artigo de Victoria Curiel, difundido no site "El Siglo":

La experiencia más interesante al visitar Berlín es experimentar cuando uno es turista cómo una ciudad puede enfrentarse con tanta dignidad y democracia a su pasado, y sobre todo con tanta creatividad e imaginación. De cada lado del exmuro florecen y crecen las librerías, las gal erías de arte, con propuestas de vanguardia tanto en las fotografías como en las instalaciones, la escultura y la pintura, artistas de todas partes del mundo acuden y abren sus talleres a los turistas; estamos en una ciudad que se está descubriendo a ella misma, y a sus pobladores, para ello basta con pasarse una mañana en el Reichstag, restaurado con su nueva cúpula de vidrio, y verán autobuses enteros de niños, adolescentes, adultos de las dos Alemanias, en fin, reunidos para visitar y reintegrar el Parlamento que fue incendiado por los grupos nazis que seguían a Hitler en 1933. Este es el espectáculo más conmovedor de Berlín reconciliado con la democracia desde los dos lados.

O s investimentos empresariais e arquitetônicos são mencionados como exemplos do novo visual da cidade:

D uas megaempresas, a Sony e a D aimler-Benz, compraram quarteirões inteiros na praça e construíram seus domínios. A Sony criou uma estrutura futurista, com uma Torre de C ristal, como chamam os alemães. Trata-se de um edifício de vidro, a sede da empresa no país, e uma arena coberta com uma cúpula, uma espécie de shopping, com cinema de tela gigantesca, cervejarias, bares, lojas e até apartamentos para morar. No dia 27 de setembro do ano passado, foi inaugurado lá o M useu do Cinema, com grande parte dos objetos usados por $M$ arlene $D$ ietrich (K leine, 2001). 
A evidência dada a arquitetos e artistas como C hristus e $D$ aniel Libeskind representa a tentativa de emprestar uma dimensão criativa à cidade. Várias fotos registram esses emblemas de um novo tempo: o museu judeu projetado com a forma da estrela-de-davi, o Reichstag, a restauração da sinagoga feita no final do governo da Alemanha 0 riental, o Sony C enter $\mathrm{e}$ a Potsdamer Platz desenhados pelo arquiteto alemão-americano $\mathrm{H}$ elmut Jahr, cujas obras expressam a face mais nova de Berlim.

É nesse momento de debate sobre o desenvolvimento urbano, permeado de construções monumentais, que se constrói a visão da cidade capaz de recuperar seu passado glorioso dos anos de 1920, ocasião em que Berlim era vista como "encarnação extrema da modernidade" (Richard, 1993), e também como cidade-capital do século XXI, conforme se pode observar nos cartazes fixados em forma de exposição no espaço em reconstrução do Palácio da República, próximo à ilha dos museus:

0 início do novo milênio mostra Berlim como metrópole de novas proporções. A imagem da capital unificada tem sido transformada por novos empreendimentos arquitetônicos espetaculares criados por artistas e arquitetos durante os últimos anos. [...] Berlim é uma cidade cujo presente, passado e futuro aparecem nitidamente diante de nossos olhos, imbuída de uma energia que inspira progresso.

O utras formas de narrar a cidade em seu passado e presente emergem intensamente depois da unificação, momento em que a "N ova Berlim" passa a fazer parte de uma rede discursiva que a projeta para além de suas fronteiras. É nesse sentido que a cidade se tornou referência para análise não só de questões como o urbanismo e a arquitetura na contemporaneidade, mas também do complexo tema da "memória histórica".

A memória como reinvenção permanente do passado

Berlim é feita de cicatrizes, de lembranças dolorosas. D e ditadura, intolerância, guerra, destruição, separação, dualidadee reunificação. Intriga pel o contraste, conquista pela riqueza de detal hes e fascina pel o passado turbulento. A história não foi esquecida. Está nas balas da Segunda Guerra, ainda incrustadas em prédios do antigo bairro judeu, nas ruínas de igrejas e sinagogas bombardeadas, nos monumentos socialistas e, claro, no que restou do muro. Por isso, o primeiro requisito para o visitante de Berlim é gostar de história (Klein, 2001). 
A descrição acima, retirada de uma reportagem especial mente dedicada a Berlim publicada no Brasil, traz registros sobre a cidade difundidos em todo o restante do mundo: as turbulências da guerra e as posteriores disputas doutrinárias signatárias da Guerra Fria.

O utras formas de evocar a cidade são menos sinistras e encantam pela figuração poética. Walter Benjamin, autor consagrado pela maneira peculiar e sensível de tratar a temática da cidade, apresenta uma das rememorações de sua infância:

En las tardes de invierno, mi madre mellevaba consigo, a veces cuando iba a hacer la compra. Era un Berlín oscuro y desconocido el que, a la luz del gas, se extendía a mi alrededor. Nos quedamos en la parte del antiguo 0 este, cuyas calles eran más uniformes y modestas que aquellas que se prefirieron más tarde. Los frisos y los miradores que constituyen el adorno de estas casas de alquiler se encontraban en la oscuridad. Pero en las fachadas se veía una luz que de manera peculiar Ilevaba hasta las ventanas. ¿Seria debido a los visillos de muselina, a las cortinas amarillas o a la camisa de una lámpara colgada? El hecho es que esta luz revelaba poco de las habitaciones iluminadas. Existía por sí misma, colocándose seductora, aunque tímida, en las ventanas. M e atraía y me hacía reflexionar. Cuando luego volvía a casa, abría mi álbum de tarjetas postales y me buscaba al H allesches Tor (1962, p. 111).

0 olhar ainda inocentede Benjamin, quemais tarde lheserviria de referência para uma elaboração crítica da modernidade, distancia-se de outras descrições contemporâneas que objetivam apresentar, a eventuais visitantes, os espaços urbanos de Berlim. 0 próprio Benjamim lamenta o desaparecimento gradual da narrativa fundada na experiência e na sensibilidade portadora de laços entre indivíduos e gerações (cf. Benjamin, 1986).

A memória de uma cidade sacraliza-se também por meio de monumentos, "a pedra", na acepção de Sennett (1994), ao lado da "carne", que define o registro da sociabilidade, anunciando formas de poder e estéticas que marcaram épocas. $\mathrm{N}$ ão por acaso a destruição e a construção de determinados monumentos estão associadas a múltiplas formas de poder.

A dimensão rememorativa aparece igualmente no relato de escritores que cristalizam momentos da vida cotidiana, tornando-se clássicos de uma época e de um lugar ${ }^{6}$. As ruínas e as imagens da devastação foram também objeto de incursão de uma literatura de registros.

Jean-M ichel Palmier (1990), que realizou uma viagem literária pelas ruas de Berlim, escolheu como ângulo de observação a estranheza, percebi-
6. Em Berlim, destacaseo célebre romancede Döblin (1995), Berlim Alexanderplat, quenarra a vida de um marginal, personagem emblemática da difícil condição desobrevivênciaem uma cidade quese modernizava ecriava, conseqüentemente, seus espaços de disciplinamento eexclusão social. Freitag (1995, pp. 127145) chama atenção para o uso da literatura como forma de identificar momentossignificativos da história de uma cidade. 
da na confrontação entre a imagem da cidade e seu passado. 0 livro é, portanto, a explicitação desse sentimento, fixado al eatoriamente em imagense encontros que mais tocaram o autor. Suas narrativas contêm a nostal gia da cidade destruída pela guerra, baseada no fato de que poucas cidades acusam tão fortemente os traços do passado como Berlim com suas ruínas. A reconstituição do passado traduz, assim, as rememorações de uma cidade desaparecida cujos vestígios não cessam de interpelar, produzindo notas nascidas da confrontação entre imaginário ereal.

Além dos traçados arquitetônicos, os lugares oficiais de culto da memória, como museus ou monumentos, realizam outra forma de lembrança, atuando como redutos de cultura com suas representações locais ou universais. Berlim, com sua ilha de museus, acena com o desejo de centralizar patrimônios da humanidade, ao mesmo tempo que designa singularidades da cultura alemã como o acervo de pintura dos expressionistas, os memoriais dos campos de concentração e os registros da história do país e da cidade.

0 tema da memória possui significação especial em uma cidade cujos processos de destruição, reconstrução, divisão e unificação parecem combinar-se ao longo do tempo, conforme a visão de H uyssen:

[...] talvez não haja outra grande cidade industrial quesuporte as marcas da história do século XX tão intensamenteedeformatão autoconscientecomo Berlim. A cidade-texto tem sido escrita, apagada e reescrita ao longo deste século violento, e sua legitimidade se deve tanto mais às marcas visíveis do espaço construído quanto às imagensememóriasreprimidaserompidaspeloseventostraumáticos (2000, p. 93).

A evocação de eventos traumáticos não se restringe à memória da guerra. Alguns guias e catálogos sobre o muro destacam determinadas ruas próximas à barreira que separava as duas Alemanhas (cf. Trotnow, 1999), principalmente a Bernauer Strasse - rua dividida ao meio pelo muro - eos acontecimentos ocorridos em suas imediações, com as tentativas de fuga da população do lado oriental para o lado ocidental. À explanação dos eventos ocorridos nesse lugar seguese a proposta de construção de um memorial, um museu que teria também a função de construir uma versão histórica, já que "poucos turistas que vieram a Berlim tinham a noção da cidade dividida".

A apresentação da cidade para os turistas não se separa de um processo simbólico de reconstrução, também articulado à presença de uma memó- 
ria trágica que atravessa, como sombra, a trajetória urbana da capital da Alemanha, conforme se lê no Guia fotográfico em cores:

Atualmente, na Berlim do terceiro milênio, no centro da União Européia, com uma moeda única e sem fronteiras, a era da fuligem das fábricas e do conservantismo burguês pertence ao passado. 0 que conta agora é a vigilância e a tolerância, um planejamento audacioso e cuidadoso, a vontade de assumir riscos e uma perseverança obstinada. Resumindo, trata-se de um mundo de contradições que os berlinenses têm que enfrentar por sua conta e risco. Esse eterno conflito entre 0 presente e o passado, entre o ruído e o silêncio, acima e abaixo, bom e mau: tudo isso é Berlim (2000, p. 5).

Ainda no âmbito dos eventos traumáticos, alguns guias turísticos refle tem as narrativas da guerra na descrição de monumentos que foram objeto de reconstrução, tornando memoráveis também lugares ligados a aconte cimentos impregnados pelas marcas do nazismo.

Fortuna (1997) aponta a valorização do significado e da função estética das ruínas, observando-as como artefatos que atualizam o passado e estimulam a construção imaginada do presente. Ao lado dos monumentos, elas são demonstrações da heterogeneidade cultural, carreando, no entanto, o perigo de se tornarem paisagem estetizada com funções similares à de mercadoria.

Em outra versão dessa temática, Simmel vê a arquitetura como vitória sublime do espírito sobre a $\mathrm{N}$ atureza, e as ruínas são percebidas como um processo de deslocamento e retorno inserido em uma totalidade. Se o que erigiu o edifício foi a vontade humana, a $\mathrm{N}$ atureza fez da obra de arte o seu material, como antes a arte se servira da $\mathrm{N}$ atureza como sua substância. $\mathrm{O}$ fato de que tudo o que é humano "vem do pó e ao pó retornará" afirma uma versão não niilista entre o "ainda não" e o "não mais". A ruína seria, na versão do autor, o ressurgimento da matéria, mas não o seu efeito trágico, constituindo-se numa direção existencial profunda. A ruína, nesse sentido, unese à paisagem e traz a impressão da paz, criando a forma presente de uma vida pretérita, o passado com seus destinos e suas mudanças. 0 que existe de sedutor na ruína é que, afinal, a obra humana é percebida como produto da natureza desgastada pelo tempo. A ausência de sedução revelase, por outro lado, quando a destruição é obra do homem. Essa é, talvez, a questão mais complexa em Berlim: suas ruínas são fruto de uma destruição causada pela guerra, e não produzida pelas marcas do tempo. 
7. A dimensão trágicados registros de destruição é estudada por Lapostolle (1981, pp. 67-76). A autora analisa o registro fotográfico da Comunade Paris, captado a partir de um duplo ponto de vista: 0 dos partidários da Comuna, que registram as barricadas e os heróis em ação, eo do lado anticomuna, quedáaosmonumentos uma aparência menos sentimental, acompanhadadeum inventário das catástrofes, um cenário de ruínas onde a presença huma na é insignificante.
A apresentação das ruínas nos guias explicita-se também pelas diferentes maneiras de fazer alusão aos dois lados da cidade por meio de espaços emonumentos que se tornaram ícones históricos. N o lado oeste, destaca-se, por exemplo, a igreja Kaiser-W ilhelm-G edächtniskirche, arrasada durante um ataque aéreo, em novembro de 1943, e conservada em ruínas. 0 "dente oco", tal como é conhecida, contém uma retrospectiva de fotos e projetos arquitetônicos do antigo templo organizados numa exposição para visitantes. 0 fato de a igreja manter a imagem de sua destruição empresta-lhe um caráter de rememoração, tornando-a emblema da devastação provocada pela Segunda G uerra M undial. "A I greja da Lembrança, Kaiser-W ilhelmG edächtniskirche, a mais bela ruína de Berlim, não será jamais reconstruída, permanecerá para sempreuma lembrança do passado" (Armin, 2000, p. 89). As ruínas dos monumentos grandiosos radicalizam o passado de devastação, tornando-se rememorações cristalizadas de evocação permanente ${ }^{7}$.

O utras imagens da destruição estão fortemente presentes nos guias da cidade, como a da N eue Synagoge, incendiada em 1943 e reconstruída em 1988. "Sua cúpula dourada, visível a longa distância, converteu-se em símbolo do bairro. Ela, que em sua época era a mais sinuosa sinagoga da cidade, foi incendiada em 1838, no transcurso da chamada 'noite dos cristais rotos', sofrendo danos adicionais durante um ataque aéreo em 1943" (Armin, 2000, pp. 60-61). A Bebelplatz, centro intelectual e artístico na época de Federico II, é também destacada devido à existência de um monumento subterrâneo que rememora a queima de livros considerados contrários ao regime, ocorrida em 1943, por ordem dos nacional-socialistas. Entre outros locais marcados pela memória da perseguição nazista, destaca-se, no referido guia, a exposição permanente da "topografia do terror", no antigo quartel geral da G estapo.

Em 1986, descobriram-se restos de calabouço e câmaras de tortura no transcurso de umas escavações realizadas no que havia sido os sótãos do edifício. D ois anos mais tarde organizou-se nesse lugar uma exposição provisória sobre a antiga central do terror nacionalista (Idem, p. 23).

0 monumento à resistência alemã homenageia conspiradores que atentaram contra o regime nazista (I dem, p. 31).

As alusões a diferentes momentos históricos contidas nos registros dos guias fazem pensar sobre as formas evocativas da memória na contempora- 
neidade. H uyssen (2000) aporta uma importante reflexão sobrea existência deuma política da memóriainstituída a partir da queda do muro deB erlim. As transformações anunciadas no livro referem-se à construção de cenários urbanos nos quais novos sentidos de memória histórica são anunciados. 0 imaginário urbano explora as lembranças traumáticas tendo como cenário a cidade de Berlim, exemplificando a volta ao passado em contraste com 0 privilégio do futuro, que constitui a marca na Europa a partir da década de 1980. Assiste-se, segundo o autor, a uma recodificação do passado, a exemplo da discussão sobre o holocausto (cf. Finkelstein, 2000), o quedemonstra a disseminação geográfica da cultura da memória e seu uso político como fenômenos que se entrelaçam e (re)fundam mitos do mundo moderno. A difusão da memória não está separada também de apropriações políticas de efeitos ideológicos, conforme se pode perceber em evocações ao holocausto.

Em Berlim convivem diferentes formas de memória, havendo mesmo um paradoxo entre as tragédias a não serem esquecidas, porque funcionam como lições para a humanidade, e a tentativa de redefini-las, com o objetivo de criar novas narrativas para a cidade. Percebe-se, portanto, que, se os guias evocam esse conjunto de tempos históricos desconexos, o fazem na suposição de que o presente carrega um passado portador de tensões e contradições.

Berlim teria também uma relação perturbada com sua ancestralidade, traduzida, por exemplo, na construção do "novo" sobre as ruínas do passado. Freitag (1994) ilustra esse paradoxo remetendo o leitor ao moderno campanário azul-transparente construído ao lado da ruína da velha torre da igreja. O utros espaços, como o da avenida U nter den Linden, apresentam essa mesma relação aparentemente contraditória entre passado e presente. Q ual seria a "verdade alemã", construída no espaço de Berlim?, indaga Freitag, e afirma que, na sua concepção, seria a vontade de dar conta do passado nazista, do holocausto, do racismo e da pulsão bélica que caracterizaram por séculos a cultura da Prússia.

As diferentes formas de expressão da memória revelam seu caráter histórico e sua base variada de significações, ora atuando como denúncia, ora como lições para a vida e para a história. As narrativas do passado também se materializam em representações simbólicas, apontando, ao pesquisador, múltiplas possibilidades de análise de seus registros.

As explanações contidas nos guias e sua função de apresentar bem a cidade instauram e legitimam narrativas que induzem o estabelecimento de rituais. $N$ esse contexto, as tragédias encontram também um lugar de 
8. Sobreessetema, éimportante atentar para a reflexão dePollak (1989, pp. 3-15) sobreamemória oficial dosjudeusem contraponto a outras lembranças reprimidas.

9. Sobrea percepção do patrimônio como cons trução histórica, ver Choay (1999). rememoração, instituindo-se como foco de atração, singularidade e exotismo. A visita aos campos de concentração ou às ruínas da guerra integra-se aos roteiros de conhecimento da cidade, afirmando o turista como flâneur ambíguo da rememoração e do esquecimento. Emerge, nessa direção, uma relação paradoxal com o passado: esquecer para não lembrar os traumas e lembrar para não repetir a história.

As múltiplas evocações do passado explicitam a dimensão plural da memória ${ }^{8}$ com seus conflitos vigentes em diferentes construções discursivas sobre a cidade 9 . O s guias e os catál ogos podem ser vistos como modos específicos de "contar a história da cidade" e fortal ecer el os entre o passado e o presente. Ressalta-se, dessa perspectiva de análise sociológica, uma me todologia de observação que pode ser ampliada a múltiplas experiências urbanas. Embora Berlim traga a peculiaridade da nitidez dos conflitos políticos eideológicos, constituindo-se numa espécie detipo ideal weberiano de disputa entre espaços, outras experiências urbanas podem explicitar questões semelhantes. N esse sentido, guias turísticos e catálogos podem ser percebidos como mapas de representações da cidade e de sua inscrição no tempo. Eles integram, portanto, uma economia específica de bens materiais e simbólicos, que tocam a relação entre cidade, memória e consumo na contemporaneidade.

Referências Bibliográficas

Armin, Dielheim Rausch (coord.). (2000), Guía de la ciudad con detalladas recomendaciones con informaciones. H eidelberg, Kunstverlag Edm. Von König.

Augé, M arc. (1998), N ão-lugares introdução a uma antropologia da supermodernidade. Venda N ova (Portugal), Bertrand Editora.

Bauman, Zygmunt. (1998), 0 mal-estar da pós-modernidade. Rio de Janeiro, Jorge Zahar.

Benjam In, Walter. (1962), Infancia en Berlín hacia 1900. M adrid, Ediciones Alfaguara

(trad. Klaus Wagner).

(1986), O bras escolhidas magia, arte técnica e política. São Paulo, Brasiliense.

Bornerman, John. (1997), “Tempo, espaço, compressão e subjetividade na Alemanha continental". In: Etnographies of urban life: symbolic, social, and spatial processes in Berlin. Berlin, Tempus Intensive Seminar/Summer School, july 20-august 3.

BRÜCKNER, Alfred \& SCHMIDT, Dietmar (orgs.). (1987), Berlin, capitaledela République

D emocratique. GDR, D resde, Intertex Berlin, verlag Zeit im Bild.

C ANCLINI, N estor G arcia. (1997), Consumidoresedidadãos Rio dejaneiro, Editora daU FRJ. 
Ch oay, Françoise. (1999), L'Allegorie du patrimoine. Paris, Éditions du Seuil.

CürLIS, Peter \& D obberke, Jüngen. (1965), Berlin 1945/Berlin heute. Laokoon Verlag, $\mathrm{GmbH}$.

DARnton, Robert. (1991), Berlin, Journal 1989-1990. N ew York/London, W. W. N orton \& Company.

D o bLin, Alfred. (1995), Berlim Alexanderplatz. Rio de Janeiro, Rocco.

EL m U Ro de Berlin, história 1961-1989. Buscando lashuellas hoy. (2001), Berlin, Jaron Verlag GM BH .

FAHR, Werner. (1965), Berlin H auptsadt der D DR. Berlin, Werbung-Beroline.

FIn KELSTEIN , N orman G. (2000), The holocaust industry: reflections on the exploitation of J ewish suffereing. London/N ew York, Verso.

FontAnE, Theodor. (1968). Wandern durch Berlin. Heidelberg, Edition European Places of Culture.

Fortuna, Carlos. (1997), “As cidades e as identidades: narrativas, patrimônios e memórias". Revista Brasileira de Ciências Sociais, 33.

FreitAG, Bárbara. (1994), "D uas cidades entre a história e a razão: homem, cidade, natureza". Revista Tempo Brasileiro, 116: 39-58.

. (1995), "Berlim: fronteiras imaginárias, fronteiras reais?". Tempo social, 16 (1-2): 127-145, jun.

GiRARDet, Raoul. (1987), M itosemitologiaspolíticas. São Paulo, Companhia das Letras. GuIA fotográfico em cores da cidade de Berlim (2000). Berlim, Rahmal-Verlag G mbH . H essel, Franz. (1997), Paseos por Berlín. M adrid, Tecnos.

H UYSSEN, Andreas. (1995), Twilight memories, marking time in a culture of amnesia.

$\mathrm{N}$ ew York/London, Routledge. - (2000), Seduzidos pela memória. Rio de Janeiro, Aeroplano.

J AQUAND, C orine. (1994), "L'insaisissable métropole”. Revue des Q uestions Allemands, D ocuments, 4.

KLEIn E, Johana. (2001), "Berlim, a cidade alemã torna-se uma referência para o mundo contemporâneo, sem esquecer seu passado". Correi o Brasiliense, C aderno Lugares, 24 jan., pp. 2-5.

Loyrette, Henri. (1992), “Latour Eiffel”. In: N ora, Pierre(org.). Le Lieux dememóire. Paris, Gallimard, vol. III, pp. 475-501.

Lapostolle, Cristine. (1981), "Plus vrai que le vrai". Actes de la Recherche, 73.

N ORA, Pierre. (1992), Les Lieux de memóire. Paris, Gallimard.

Palmier, Jean-M ichel. (1990), Retour à Berlin. Paris, Payot.

Pollak, M ichael. (1989), "M emória, esquecimento, silêncio". Estudos H istóricos, 3.

RICHARD, Lionel. (1993), Berlim, 1919-1933: A encarnação extrema da modernidade. Rio de Janeiro, Jorge Zahar. 
Sennett, Richard. (1994), Carne e pedra, o corpo e a cidade na civilização ocidental. Rio de Janeiro, Record.

Sim mel, G eorg. (1976), “A metrópole ea vida mental”. In: VelHo, O ctávio Guilherme (org.). 0 fenômeno urbano. Rio de Janeiro, Jorge Zahar. . (1998), “A ruína”. In: Souza, Jesse \& O elze, Berthold. Simmel e a modernidade. Brasília, Editora da UnB.

Stein, M ary Beth. (1997), "Remembering August 13 in East and West Berlin". Ethnographies of urban life: symbolic, social, and spatial processes in Berlin. Berlin, Tempus Intensive Seminar/Summer Scholl, july 20-august 3, pp. 119-143.

T ROT N Ow, H elmutt. (1999), "U nderstanding the present by looking back at the past". Berlin Wall, Berlin, Jeron Verlag G mbH .

W alk the wall. Pharus Plan. H aus am Checkpoint Charlie/Pharus-Verlag H einrich Möller KG, english edition.

\section{Resumo}

Os guias turísticos em Berlim

Este artigo aborda o tema das narrativas sobre a cidade de Berlim presentes em folhetos, livros de história e guias turísticos, em distintos momentos históricos: o período pós-guerra, a época da divisão (Lestee 0 este) e o momento mais recente de reunificação, condizente com a instituição de uma capital multicultural. As reflexões acentuam o modo como diferentes espaços, monumentos e edificações são evocados e submetidosa processos simbólicos, processos esses que revelam disputa entre memórias eapontam constantes red efinições da rel ação entre passado e presente. Ressalta-se, dessa perspectiva de análise, uma metodologia de observação sobre as narrativas da cidade que pode ser ampliada a outras experiências urbanas.

Palavras-chave: Cidade; M emória; Turismo; N arrativa.

\section{Abstract}

The tourist guides in Berlin

This paper deals with the narratives about Berlin as can be found in leaflets, history

Texto recebido em 5/ 4/2004 eaprovado em 9/12/2004.

Irlys Alencar Firmo Barreira é professora titular do ProgramadePós-Gra duação em Sociologiada UniversidadeFederal do Ceará. E-mail: ialencar @secrl.com.br. books and travel guides, at different historical moments: the post-war period, the division of the State (East-West) and more recently, at the time of reunification, when it became worthy of being instituted as a multicultural capital. The discussion highlights the way different spaces, monuments and buildings are recalled and embedded in symbolic processes, that reveal a dispute among memories and that point to constant redefinitions of the relation between past and present. From this point of view, it is possible to realize that the observation methods of the city narratives may be expanded and applied to other urban experiences. Keywords: City; M emory; Tourism; N arratives. 